\title{
Lightning and convection parameterisations - uncertainties in global modelling
}

\author{
H. Tost, P. Jöckel, and J. Lelieveld \\ Atmospheric Chemistry Department, Max Planck Institute for Chemistry, P.O. Box 3060, 55020 Mainz, Germany
}

Received: 13 April 2007 - Published in Atmos. Chem. Phys. Discuss.: 21 May 2007

Revised: 14 August 2007 - Accepted: 17 August 2007 - Published: 5 September 2007

\begin{abstract}
The simulation of convection, lightning and consequent $\mathrm{NO}_{\mathrm{x}}$ emissions with global atmospheric chemistry models is associated with large uncertainties since these processes are heavily parameterised. Each parameterisation by itself has deficiencies and the combination of these substantially increases the uncertainties compared to the individual parameterisations. In this study several combinations of state-of-the-art convection and lightning parameterisations are used in simulations with the global atmospheric chemistry general circulation model ECHAM5/MESSy, and are evaluated against lightning observations. A wide range in the spatial and temporal variability of the simulated flash densities is found, attributed to both types of parameterisations. Some combinations perform well, whereas others are hardly applicable. In addition to resolution dependent rescaling parameters, each combination of lightning and convection schemes requires individual scaling to reproduce the observed flash frequencies. The resulting $\mathrm{NO}_{\mathrm{x}}$ profiles are inter-compared, however definite conclusions about the most realistic profiles can currently not be drawn.
\end{abstract}

\section{Introduction}

Lightning represents one of the most energetic phenomena in the Earth's atmosphere. In the troposphere flashes are the only natural process that can break up the highly stable triple bonds of molecular nitrogen, transforming $\mathrm{N}_{2}$ into reactive nitrogen species which strongly influence the chemistry of the upper troposphere (e.g. Labrador et al., 2005; Schumann and Huntrieser, 2007, and references therein). Therefore, an accurate representation of lightning in global models of the atmosphere is crucial. Additionally, lightning represents an

Correspondence to: $\mathrm{H}$. Tost

(tost@mpch-mainz.mpg.de) important factor in the ignition of wild fires (e.g. Jacobson, 2002).

In contrast to small scale process models (e.g. Barthe et al., 2005) atmospheric chemistry general circulation models (AC-GCMs) generally do not represent the global electrical circuit, e.g. the electrical field and the detailed processes involved in cloud electrification and discharges. Instead the lightning and the subsequent $\mathrm{NO}_{\mathrm{x}}$ formation are determined with the help of (semi-)empirical parameterisations. Since it is difficult to measure such emissions in situ or by remote sensing, there is a high uncertainty in the total amount of $\mathrm{NO}_{\mathrm{x}}$ globally produced by lightning, i.e. ranging from 2 to $8 \mathrm{Tg}$ N/yr (e.g. Schumann and Huntrieser, 2007).

The occurrence of flashes on the other hand can be observed from satellites, e.g. the LIS/OTD missions (Christian et al., 1999, 2003; Thomas et al., 2000), and an extensive climatology has been established over the last decade and has been used for comparisons with parameterisations. Even if the occurrence of flashes could be predicted accurately by the model, uncertainties in the $\mathrm{NO}_{\mathrm{x}}$ emissions remain, since the amount of $\mathrm{NO}_{\mathrm{x}}$ produced per flash is not a constant. It varies with flash strength, extension, type, branching, and additional aspects. The amount of $\mathrm{NO}_{\mathrm{x}}$ per flash in a "typical thunderstorm" varies by more than an order of magnitude $\left((2-40) \times 10^{25} \mathrm{NO}\right.$ molecules per flash, Schumann and Huntrieser, 2007). Nevertheless, the accurate prediction of flash occurrence is a prerequisite to estimate lightning produced $\mathrm{NO}_{\mathrm{x}}$ emissions in the upper troposphere.

A problem with most parameterisations (some will be described in detail below) is that they are mainly derived empirically from correlations between other observable quantities. However, their applicability to the global scale and extended time periods of several years is limited since the heterogeneity of phenomena can only be represented approximately. Nevertheless, these parameterisations are used in global AC-GCMs since the assimilation of observed flashes at every model time step is computationally not feasible and

Published by Copernicus Publications on behalf of the European Geosciences Union. 
not necessarily consistent with the desired occurrence of convection in the model. Furthermore, for the calculation of future scenarios such techniques are not applicable and the lightning has to be parameterised.

Petersen and Rutledge (1998) found a relationship between convective precipitation and lighting with the goal to estimate the rain rate from observed flashes. Even though a precipitation estimate can be made from lightning events, this study concludes that this is only valid for long-term averages, and not to individual precipitation and related lightning events (Petersen and Rutledge, 1998). Further studies of Petersen et al. (2005) combining satellite observations of precipitation ice water content and flashes show that the correlation of these two parameters can be applied globally, almost for individual events, but unfortunately convection parameterisations include too strongly simplified cloud microphysics so that the ice water content is difficult to determine accurately. Therefore, the implementation of a lightning parameterisation for GCMs based on the ice water content is not straight-forward.

On the other hand, the simulation of lightning based on convection parameterisations offers the possibility to investigate how realistic these schemes describe the processes. In a previous study (Tost et al., 2006) we analysed convection on a global scale with respect to temperature and the hydrological cycle using several convection parameterisations, but did not discuss the convective dynamics, e.g. the convective mass fluxes. With the help of the updraft based lightning schemes (details below), the updraft strength can be correlated to the observable quantity of flashes.

The next section introduces the model and the parameterisations used, Sect. 3 the simulation setup, Sect. 4 presents the analysed results, and the conclusions are given in Sect. 5.

\section{Model description}

In this study the AC-GCM ECHAM5/MESSy (E5/M1) (Jöckel et al., 2006) has been applied. It is based on the general circulation model ECHAM5 (Roeckner et al., 2006) (version 5.3) and the Modular Earth Submodel System (Jöckel et al., 2005) (version 1.3).

Most of the meteorological processes are calculated by ECHAM5 based on a spectral representation of the prognostic variables vorticity, divergence, temperature, and the logarithm of the surface pressure, as well as grid point representations of specific humidity, cloud water, and cloud ice. In the vertical a hybrid pressure coordinate system is applied. The processes of radiation and cloud microphysics are parameterised, as described in the ECHAM5 documentation (Roeckner et al., 2003, 2004).

Additionally, the MESSy infrastructure and some of the submodels, i.e. an extended convection submodel (Tost et al., 2006) containing additional parameterisations, an extended lightning $\mathrm{NO}_{\mathrm{x}}$ emission submodel (LNOX) and the diagnos- tic tropopause and planetary boundary layer height submodel (TROPOP) have been used. The output frequency for the lightning and convection data for this study is set to hourly average values, and to six hourly averages for the other meteorological data.

\subsection{Convection parameterisations}

The convection parameterisations included in the CONVECT submodel are:

- The Tiedtke (1989) scheme with modifications by Nordeng (1994) (further denoted as T1). This scheme is used as the default convection parameterisation.

- The convection parameterisation of the operational ECMWF model (IFS cycle 29r1b (Bechtold et al., 2004, and references therein), denoted as EC), which is a further development of the Tiedtke (1989) scheme;

- The Zhang-McFarlane-Hack scheme (Zhang and McFarlane, 1995; Hack, 1994) (ZH) as applied in the MATCH model (Rasch et al., 1997; Lawrence et al., 1999) and a version with an extended evaporation scheme (Wilcox, 2003), denoted as ZHW;

- The scheme of Bechtold et al. (2001), denoted as B1.

For a more detailed comparison of these schemes, their detailed configurations and extensions, and their influence on the hydrological cycle we refer to Tost et al. (2006) and Tost (2006).

\subsection{Lightning parameterisations}

The LNOX submodel applied in this study encompasses the widely used lightning $\mathrm{NO}_{\mathrm{x}}$ parameterisation by Price and Rind (1992) with further updates (Price and Rind, 1993, 1994; Price et al., 1997a,b) based on the correlation between the convective cloud top height (in the model determined as the altitude of the top level, in which a convective updraft mass flux is calculated) and the occurrence of flashes derived

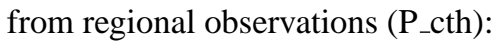

$F_{c}=3.44 \times 10^{-5} \cdot H^{4.90}$
$F_{o}=6.40 \times 10^{-4} \cdot H^{1.73}$,

with $F_{c}$ representing the continental and $F_{o}$ the oceanic flash frequencies and $H$ the convective cloud top height in kilometres above ground. For each grid box the total flash frequency is determined with the fractional land-sea mask.

In addition, the parameterisation by Grewe et al. (2001) is included, linking updraft velocity as a measure of convective strength and associated cloud electrification with the flash frequency (G_updr):

$F=1.54 \times 10^{-5} \cdot\left(w \cdot d^{0.5}\right)^{4.9}, \quad$ with : 


$$
\begin{aligned}
& d=\sum_{i=\text { cloud bottom }}^{\text {cloud top }} h_{i} \\
& w=\sum_{i=\text { cloud bottom }}^{\text {cloud top }} \frac{M_{i}}{\rho_{i}} \cdot \frac{h_{i}}{d} .
\end{aligned}
$$

$F$ is the flash frequency, $w$ the updraft velocity, $h_{i}$ the grid box height, $d$ the cloud thickness, $M_{i}$ the updraft mass flux and $\rho_{i}$ the air density. Note that there is no differentiation between land and sea, assuming that the weaker intensity of convection (and consequently less intense cloud electrification) over the ocean is represented adequately by the convection parameterisation.

Allen and Pickering (2002) propose two additional polynomial parameterisations for lightning occurrence, one also based on the updraft strength at a specific altitude (A_updr):

$F_{c g}=a+b \cdot M+c \cdot M^{2}+d \cdot M^{3}+e \cdot M^{4}$,

and another on the amount of convective precipitation at the surface (A_prec):

$F_{c g}=a_{i}+b_{i} \cdot P+c_{i} \cdot P^{2}+d_{i} \cdot P^{3}+e_{i} \cdot P^{4}$

with $M$ the updraft mass flux at an altitude of $0.44 \sigma^{1}$, and $\mathrm{P}$ the convective precipitation at the surface (only for precipitation stronger than $7 \mathrm{~mm} /$ day). The parameters ${ }^{2}$ are constants taken from Allen and Pickering (2002) without any modifications, considering the lightning scheme was proposed as a scheme for global models.

For the total flash frequency (over both land and ocean) calculated with the A_prec scheme a weighting with the fractional land-sea mask has been applied (similar to the P_cth scheme). Note that these polynomial parameterisations determine the cloud-to-ground flashes $\left(F_{c g}\right)$ only, whereas the first two approaches give the total flash frequency (cloud-toground and in-cloud). Nevertheless, with the help of the relationship between cloud-to-ground and total flash frequency by Price and Rind (1993), for all four schemes the total amount of flashes and the fractionation into cloud-to-ground and in-cloud can be determined.

The amount of $\mathrm{NO}_{\mathrm{x}}$ emitted by lightning is calculated using a number of $6.7 \times 10^{26}$ molecules/flash $(\approx 15.6 \mathrm{~kg} \mathrm{~N} / \mathrm{flash})$ for cloud-to-ground flashes. The ratio of $\mathrm{NO}_{\mathrm{x}}$ production by IC flashes is lower by a factor of 0.1 . Both these numbers are uncertain, but are within the range proposed by Schumann and Huntrieser (2007).

\footnotetext{
${ }^{1}$ In this case $\sigma$ is the ratio between pressure and surface pressure.

${ }^{2}$ The index $i$ in Eq. (4) represents land $(l)$ or ocean $(o)$, the values are as follows: $a=-2.34 E-2, b=3.08 E-1, c=-7.19 E-1$, $d=5.23 E-1, e=-3.71 E-2$ and $a_{l}=-3.75 E-2, b_{l}=-4.76 E-2$, $c_{l}=5.41 E-3, d_{l}=3.21 E-4, e_{l}=-2.93 E-6$, and $a_{o}=-5.23 E-2$, $b_{o}=-4.80 E-2, c_{o}=5.45 E-3, d_{o}=3.68 E-5, e_{o}=-2.42 E-7$; the corresponding units are chosen such that after the multiplication with the respective quantity the unit of a flash frequency $(1 / s)$ is achieved.
}

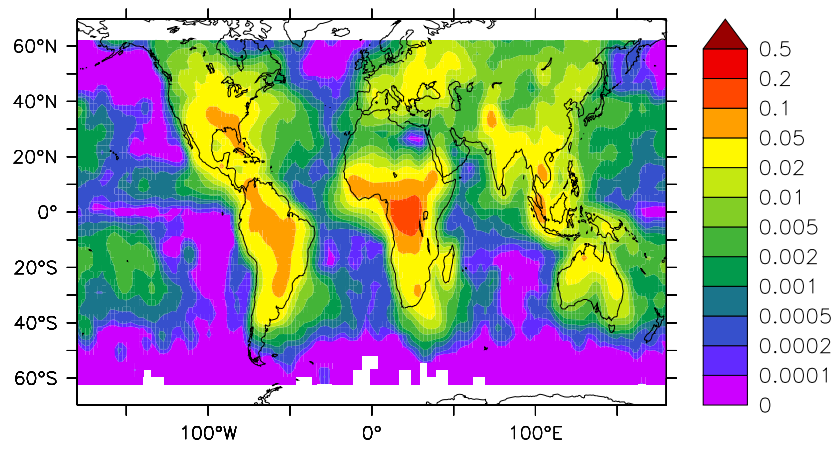

Fig. 1. Observed annual average flash density in flashes $/\left(\mathrm{km}^{2}\right.$ day $)$ for the year 1999 from LIS/OTD data from $60^{\circ} \mathrm{S}$ to $60^{\circ} \mathrm{N}$.

\section{Simulation setup}

A set of five simulations has been performed with a horizontal resolution of $\mathrm{T} 42\left(\approx 2.8^{\circ} \times 2.8^{\circ}\right.$ of the corresponding quadratic Gaussian grid) and 31 layers in the vertical direction (the midpoint of the uppermost layer is at $10 \mathrm{hPa}$ ). In each simulation all four lightning parameterisations are applied simultaneously and the emitted $\mathrm{NO}_{\mathrm{x}}$ is vertically distributed according to a parameterisation of Pickering et al. (1998). Horizontal resolution dependent scaling factors for the flash densities have been applied as proposed in the original articles describing the lightning parameterisation schemes. The individual simulation setups differ only with respect to the convection scheme selected via a namelist. Consequently, all simulations have been performed with the same executable. Because of the feedback of the convection on the atmospheric dynamics, the meteorology is different for each simulation.

The simulation has been performed for the year 1999, with several months of model spin-up. To overcome the issue of different meteorology in the various simulations the "nudging" (Newtonian relaxation) technique (Jeuken et al., 1996; van Aalst et al., 2004; Jöckel et al., 2006) with ECMWF operational analysis data of vorticity, divergence, temperature and surface pressure for the year 1999 is applied in the free troposphere with a similar nudging profile as in Jöckel et al. (2006). Even though the influence of the nudging is relatively small (the nudging coefficients are comparable to Jöckel et al., 2006), it is sufficient to achieve similar meteorological patterns as observed in this specific year.

\section{Results}

Observational datasets

Observed lightning data is used from the LIS (Christian et al., 1999; Thomas et al., 2000) and OTD (Christian 
Table 1. Scaling factors for the combination of lightning and convection parameterisations.

\begin{tabular}{ccccc}
\hline & P_cth & G_updr & A_updr & A_prec \\
\hline T1 & 5.92 & 4.28 & 4.22 & 2.78 \\
EC & 2.14 & 1.37 & 5.26 & 5.52 \\
ZH & 0.87 & 434.73 & 148.18 & 24.27 \\
ZHW & 0.74 & 227.32 & 114.95 & 18.69 \\
B1 & 1.36 & 1.35 & 20.74 & 3.97 \\
\hline
\end{tabular}

et al., 2003) satellite instruments ${ }^{3}$. In this study the gridded products of the time series for the year 1999 (LISTOTD_LRTS_V2.2) are applied as well as annual and daily climatologies (LISTOTD_HRADC_V2.2 at high $\left(0.5^{\circ}\right)$ and LISTOTD_LRADC_V2.2 at low $\left(2.5^{\circ}\right)$ resolution).

Additionally, satellite data from the Tropical Rainfall Measuring Mission (TRMM) (Kummerow et al., 2000), i.e. the $3 \mathrm{~A} 25$ and the $3 \mathrm{~B} 42$ products $^{4}$, are used for the comparison of lightning data with observed convective cloud properties (convective precipitation, cloud top height, i.e. the convective storm height). This is suitable since all satellite products are obtained from the same orbital platform. Even though the observations are also associated with uncertainties (Christian et al., 1999; Thomas et al., 2000; Christian et al., 2003) resulting from the sampling frequency, grouping of flashes, a bias of the sensor, etc., in this study these factors are ignored and the measured data is treated as being accurate.

\subsection{Annual average lightning distributions}

Figure 1 shows the annual average flash density for the year 1999 taken from the long-term time series of observed flashes from combined LIS and OTD data, i.e. the LISOTD_LRTS_V2.2 dataset. The displayed region is restricted to $60^{\circ} \mathrm{S}$ to $60^{\circ} \mathrm{N}$ because of the viewing angle of the satellite. The observed maxima occur over the continents, especially in Central Africa, with secondary maxima over South America and the islands of the maritime continent. Note that the colour scale of Fig. 1 is logarithmic, because of the large contrast in flash densities over the continents and the oceans.

Figure 2 shows the simulated flash densities with the different convection and lightning parameterisations. The colour scale is identical to that of Fig. 1. However, the simulated flash frequency had to be rescaled with the average number of flashes per second over the globe (48.81 flashes/s

\footnotetext{
${ }^{3}$ Obtained from the Global Hydrology Resource Centre: http: //thunder.msfc.nasa.gov/data/.

${ }^{4}$ Monthly mean gridded data (3A25) and 3 hourly gridded precipitation (3B42) from the precipitation radar, a $13.8 \mathrm{GHz}$ radar, one of three rain instruments on board the TRMM satellite, with the possibility to retrieve three-dimensional precipitation characteristics.
}

for the year 1999, regridded on the model coordinates, from $60^{\circ} \mathrm{S}$ to $60^{\circ} \mathrm{N}$ ). The scaling factors for the different model setups are listed in Table 1.

This scaling, in addition to the resolution dependent rescaling mentioned above in the formulation of the lightning parameterisation, is needed for comparison and forces the results into the observed range. These scaling factors differ by almost three orders of magnitude, showing the large variation of the input data from the different convection schemes for each of the lightning parameterisations.

Using the P_cth parameterisation based on the convective cloud top height (Eq. (1), first column of Fig. 2) all simulations show the strong contrast between ocean and land. However, the oceanic flash densities are systematically too low by approximately a factor of 1.5 to 10 , independent of the choice of the convection scheme $e^{5}$ This originates from the weaker exponential dependency of the cloud top height and the calculated flash frequency (compare Eq. 1). Consequently, the continental flash densities are overestimated. The maximum values occur mainly over South America, whereas the high flash densities over Africa are captured only with the $\mathrm{ZH}$, the ZHW and the B1 simulation (lower three panels of the first column). The other simulations show lower average cloud top heights over Central Africa mainly caused by a lower number of convective lightning events in that region. Except for the EC simulation the simulated lightning activity over the maritime continent is substantially overestimated. Since the cloud top height does not differ significantly between land and sea grid cells in that region, this is a result of the different treatment in the $\mathrm{P}_{-}$cth convection parameterisation. Over the tropical oceans the ZH and ZHW simulation are characterised by substantially higher cloud top heights compared to the other simulations. From the parameterised flash frequencies this is not obvious, since the oceanic flash frequency shows a lower dependence with the vertical extension of the cloud, as mentioned above. The annual average cloud top height (mean over convective and non-convective cases) is lowest in $\mathrm{T} 1$, slightly higher in EC and $\mathrm{B} 1$ and highest in $\mathrm{ZH}$ and ZHW. This results partly from deeper convection (as analysed in Tost, 2006), but also in the frequency of lightning producing convective events: in the $\mathrm{ZH}$ and $\mathrm{ZHW}$ simulation in the tropics the convection scheme triggers lightning activity in $60 \%$ to $100 \%$ of the time due to the high convective cloud tops. This is caused by the too frequent activation of the adjustment scheme of Hack (1994) of the ZH convection parameterisation (compare Tost et al., 2006). This value is much lower for the other three model configurations (T1, $\mathrm{EC}$, and B1). In the midlatitudes of the northern hemisphere the simulated flash density in all simulations is lower than observed, most pronounced in the southern part of the USA,

\footnotetext{
${ }^{5}$ The average values of the ratio $f f_{\text {sim }} / f f_{\text {obs }}$ over the ocean for $\mathrm{T} 1$ are $\approx 0.54$, for $\mathrm{EC} \approx 0.46$, for $\mathrm{ZH}$ and $\mathrm{ZHW} \approx 0.79$, and for $\mathrm{B} 1 \approx 0.37$, but local differences can be substantially larger.
} 

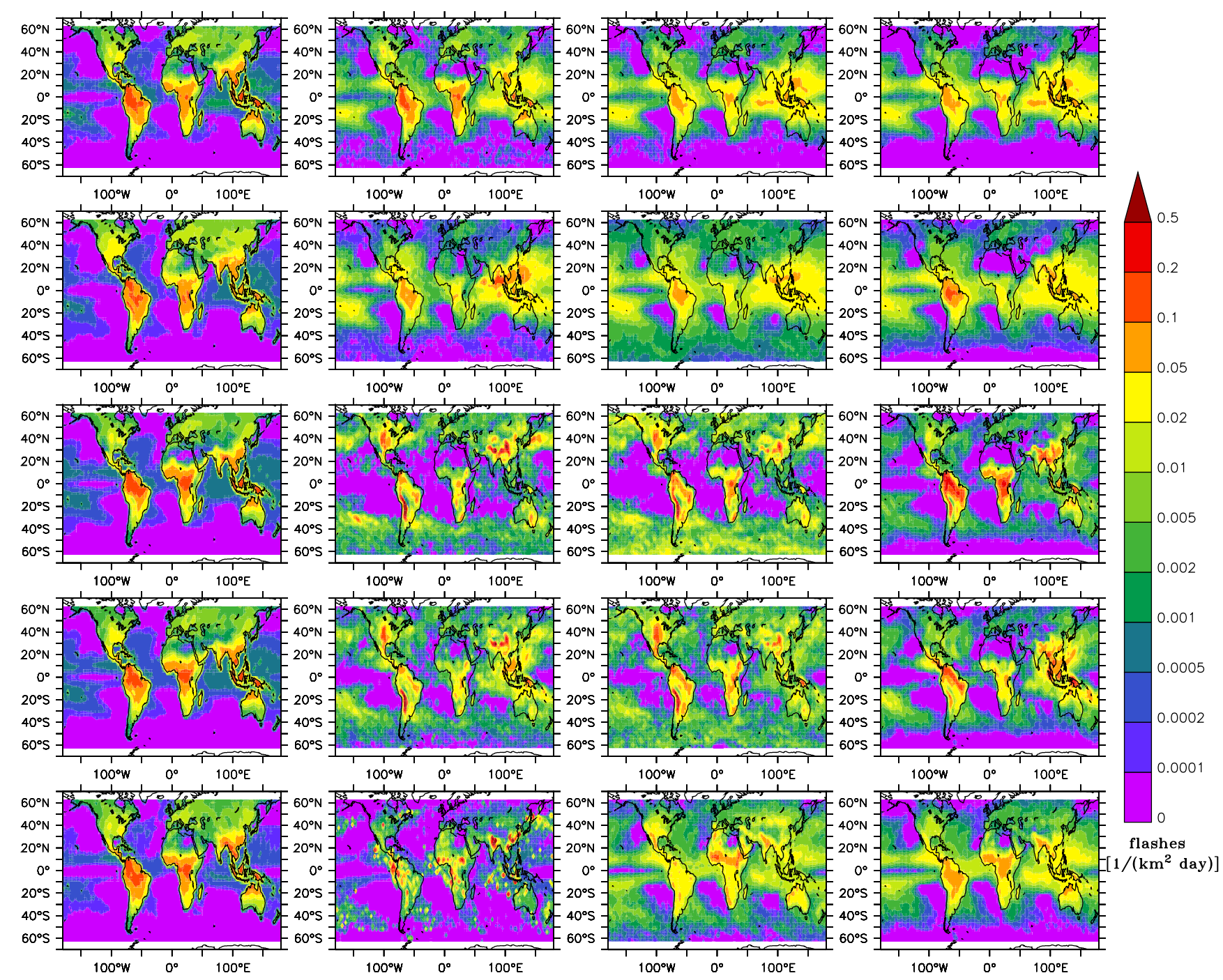

Fig. 2. Simulated annual average flash densities from $60^{\circ} \mathrm{S}$ to $60^{\circ} \mathrm{N}$ in flashes/( $\mathrm{km}^{2}$ day). The rows represent the different convection schemes (T1, EC, ZH, ZHW, B1 from top to bottom), whereas the columns depict the different lightning parameterisations (P_cth, G_updr, A_updr, A_prec from left to right).

caused by too low lightning activity during the boreal winter months.

The updraft based lightning parameterisation of Grewe et al. (2001) (Eq. (2), second column of Fig. 2) overestimates the lightning activity over the oceans compared to the observations. The too high flash frequencies result from the similar strength of the convective mass fluxes over ocean and land and not - as required by the basic assumptions of the lightning scheme - from less intense convective activity over the ocean. This is a general weakness of convective bulk mass flux schemes (it appears in all five simulations) that only compute mean updraft mass fluxes for the whole grid cell. These schemes consequently cannot differentiate between strong convection over a small (subgrid-scale) area and weak convection over a large (subgrid-scale) area. To overcome this weakness of the convection schemes in the lighting parameterisation different parameters should be chosen for land or ocean grid boxes. However, using the unmodified scheme of Grewe et al. (2001) without differentiation between ocean and land the overestimation must be attributed to the convection parameterisations. In combination with the $\mathrm{T} 1$ and $\mathrm{EC}$ convection schemes the simulated flash density generally represents the observed patterns except for the overestimation over the tropical oceans. Furthermore, the African maximum is underestimated. The T1/G_updr combination (second panel in the first row) yields only slightly lower values in the southern USA than observed, whereas in Siberia the occurrence of flashes is significantly underestimated. The simulations with the ZH and ZHW convection schemes are characterised by significant lightning in the 
midlatitude storm tracks, with an almost negligible land-sea contrast, and stronger differences over land and sea in the tropics and subtropics. The first aspect is likely caused by the activation of the Hack (1994) convective adjustment that is part of the $\mathrm{ZH}$ and $\mathrm{ZHW}$ convection scheme, leading to more convective activity and less large-scale clouds. The second aspect is caused by the less frequent triggering of the deep convection part (Zhang and McFarlane, 1995) over the oceans. In some regions, especially over mountain slopes (Himalaya, Andes) very high flash densities are calculated. The latter effect results mainly from the convection scheme which computes high convective mass fluxes in these locations (orographically forced convection). The combination of the B1 convection with the G_updr lightning results in very spotty flash occurrences, which do not reproduce the observed flash distribution well. This is caused by rare, unrealistically strong convective updraft events, produced by the Bechtold et al. (2001) convection scheme. Consequently, due to the strong exponential dependency of the lightning frequency on the vertical velocity, this yields overestimated flash densities. Applying the same mass fluxes with the A_updr scheme (using the updraft strength at $0.44 \sigma$, i.e. approx. $500 \mathrm{hPa}$ ) these spikes do not occur (compare third panel of the last row). This indicates that the intense flash frequencies are likely caused by the occurrence of unrealistically strong shallow convection that affects the mean vertical velocity (according to Eq. 2c) within the clouds. The overall flash frequency with this lightning parameterisation is lower than with the P_cth approach in combination with all convection schemes (highest values still with $\mathrm{ZH}$ and $\mathrm{ZHW}$ over the continents), but the differences in the number of lightning events between the simulations are smaller.

Using the polynomial function of updraft for the flash frequency (A_updr, Eq. 3), the lightning over the ocean is even more strongly overestimated as with G_updr, and the continental maxima are substantially underestimated when it is applied in combination with the T1 and EC convection (upper two panels of the third row of Fig. 2). Furthermore, the extratropical continental lightning density is too low. In combination with the ZH and ZHW convection a similar distribution as with the G_updr occurs with the maxima at the same locations, however, not capturing the observed ones, especially over the continents. This cannot be attributed to shallow convection, but rather to the total number of convective events which produce lightning. Moreover, the updrafts in the middle and upper troposphere are substantially weaker compared to the other convection schemes, which leads to the high rescaling factors for these combinations (Table 1). Yet they are more widely distributed over large regions. As mentioned above, the strong activity in the storm tracks results from the setup of the convection parameterisation, i.e. the too frequent activation of the Hack (1994) convective adjustment instead of the deep convection of Zhang and McFarlane (1995). This results in the overestimation of the convection activity (compare Tost et al., 2006). In contrast, the combination with the $\mathrm{B} 1$ convection results in a much smoother lightning distribution. The absolute maximum in Central Africa is shifted too far northward, and the flash density is overestimated over the tropical oceans, while localised events such as with G_updr do not occur if the mass flux at about $500 \mathrm{hPa}$ is used to determine the number of flashes. The resulting flash densities of the A_updr lightning parameterisation show some similarities with respect to the global annual average distribution with the T1, EC and B1 convection. Consequently the typical features, i.e. the overestimation over the ocean and underestimation of the continental maxima are likely to be attributed to the lightning scheme.

The precipitation based approach of Allen and Pickering (2002) (A_prec, Eq. 4) combined with the T1 convection (upper panel in the last row) does not reproduce the observed land-sea contrasts similarly to the T1/A_updr setup. The maximum in Central Africa is underestimated as well as the flash densities in Europe, North America and Siberia. On the other hand, the values in the ITCZ over all oceans, the warm pool region and the SPCZ are overestimated by a factor of 5 to 10 resulting from an overestimated convective precipitation yield (Tost et al., 2006). In combination with the EC convection scheme the oceanic flash density is overestimated compared to the observations, but less significantly than with the T1/A_prec approach. The lower oceanic lightning activity results from the lower total amount of convective precipitation produced in this regions than with $\mathrm{T} 1$ (compare Tost et al., 2006). In South America slightly higher values than observed are simulated, and the maximum over Central Africa is poorly reproduced. Similarly to T1, the occurrence of lightning in the continental midlatitudes of the Northern hemisphere is underestimated, since the contribution of convective precipitation during frontal passages is too low, i.e. the midlatitude precipitation associated with frontal nimbostratus is not mainly produced by the convection but by the large-scale condensation scheme in these two model configurations. The $\mathrm{ZH}$ and $\mathrm{ZHW}$ convection schemes, which yield a strong difference between precipitation over land and sea (Tost et al., 2006), capture the distribution slightly better, but strongly overestimate the flash frequency over the tropical continents (especially ZH). On the other hand, in the midlatitudes continental lightning is underestimated, although the differences to the observations are lower than with the other convection schemes. However, since the precipitation distribution of neither $\mathrm{ZH}$ and $\mathrm{ZHW}$ does correspond well to the observations (Tost et al., 2006), a better agreement with the observed flash densities is likely the result of compensating "misconceptions" in both lightning and convection parameterisations. The combination of B1 and A_prec results in a more realistic distribution of the annual average flash density. Even though the maximum over Central Africa is underestimated, and the values over the tropical oceans are overestimated, the general patterns are captured quite well (comparable to the T1/G_updr combination) without any extreme values over specific locations. This is a direct result 


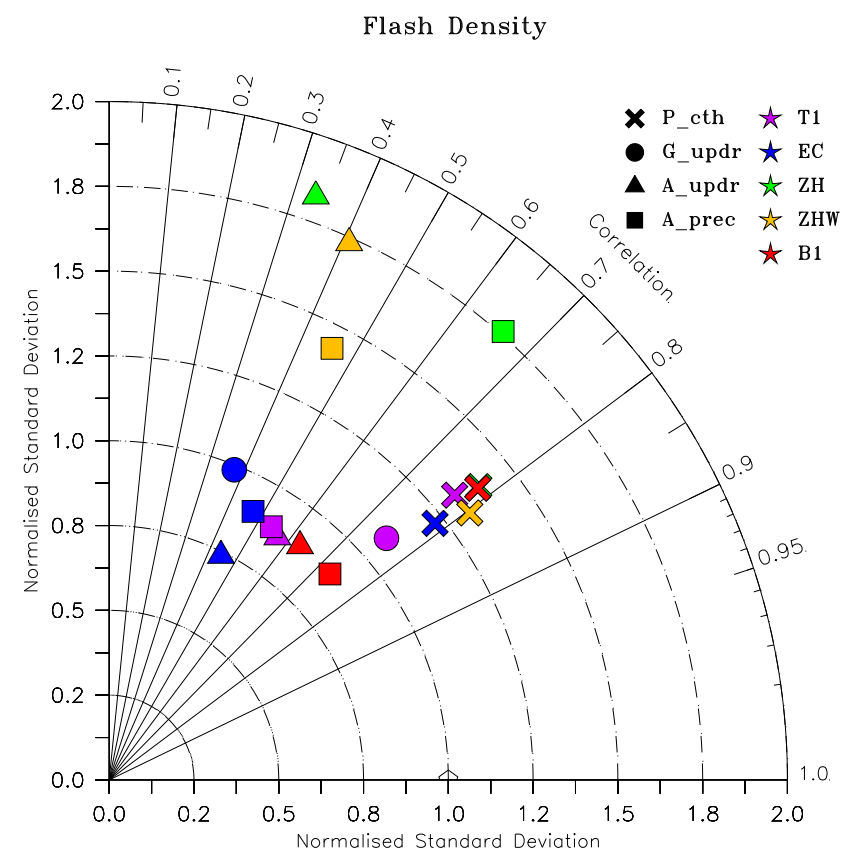

Fig. 3. Taylor diagram for the various combinations of convection and lightning schemes compared with LIS/OTD data, showing the spatial standard deviation of the calculated flash densities normalised with the standard deviation of the observations $\sigma^{\star}$ (on the radial axis), the spatial correlation $R$ (the angle) and the corresponding RMSE (distance from the point marked with the open box with correlation of one and normalised standard deviation of one). The different convection schemes are depicted by the colours, and the lightning parameterisations by the symbols.

of the relatively good agreement between the simulated and observed precipitation patterns.

A statistical comparison of the observed and simulated annual average flash densities is shown in the Taylor diagram in Fig. 3 (Taylor, 2001). In combination with the P_cth scheme the overall performance of all convection schemes is very similar (all "X"s are closely together, the green and the red ones overlay). This indicates a very robust behaviour of this approach: even though the cloud top height differs and depends on the scheme, the average distribution agrees well in all simulations. The correlation $(R \approx 0.75$ to 0.8$)$ is highest for these combinations, but the spatial variation is slightly overestimated $\left(\sigma^{\star} \approx 1.2\right.$ to 1.4 with $\left.\sigma^{\star}=\sigma_{\text {sim }} / \sigma_{\text {obs }}\right)$. The rescaling factors of Table 1 therefore result mainly from the different frequencies of lightning producing convective events, which is much higher in case of the $\mathrm{ZH}$ and $\mathrm{ZHW}$ convection schemes. The T1/G_updr combination achieves a similar spatial correlation, and the lower $\sigma^{\star}$ indicates an even better performance in this simulation setup. However, this approach is not working well with the other convection parameterisations since it is highly dependent on the vertical updraft velocity and easily deteriorated by less realistic convective dynamics. While $R$ is much lower for EC/G_updr, $\sigma^{\star}$
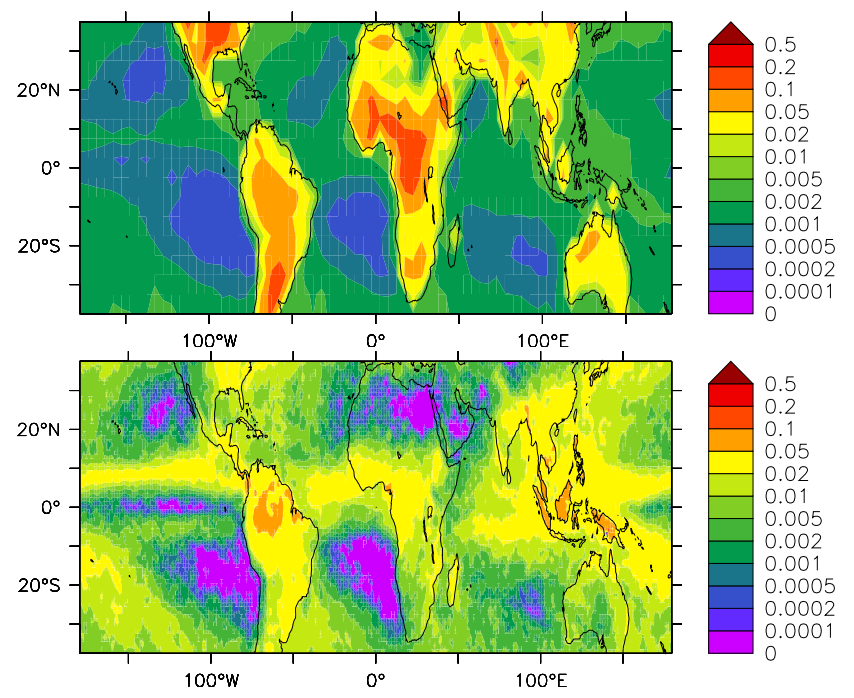

Fig. 4. Parameterised annual average flash density (in flashes $/\left(\mathrm{km}^{2}\right.$ day)) calculated from TRMM monthly mean cloud top height data for the year 1999, applying the P_cth scheme (upper panel) and calculated from TRMM 3 hourly precipitation data using the A_prec parameterisation (lower panel). The lightning activity has been rescaled to the observations (see text).

is close to one, whereas the symbols for $\mathrm{ZH}, \mathrm{ZHW}$ and $\mathrm{B} 1$ are out of scale $\left(\sigma^{\star}>2\right)$. The polynomial function of lightning and mass fluxes at about $500 \mathrm{hPa}$ is slightly more robust, but shows a large scatter in combination with the convection parameterisations. None works as well as the $\mathrm{P}_{-}$cth approach with respect to both spatial correlation and variation. The precipitation based approach underestimates the spatial variation for $\mathrm{T} 1, \mathrm{EC}$, and $\mathrm{B} 1$, but overestimates it for $\mathrm{ZH}$ and ZHW. This results from the disagreement of the precipitation distributions with the observations of the latter two schemes (Tost et al., 2006). Especially the combination B1/A_prec works almost as well as T1/G_updr in capturing the observed flash density distribution.

\subsection{Applicability of lightning parameterisations}

To check the applicability of the lightning parameterisations monthly mean values for the convective storm height ${ }^{6}$ between $40^{\circ} \mathrm{N}$ and $40^{\circ} \mathrm{S}$ are used with the $\mathrm{P}_{-}$cth scheme as depicted in the upper panel of Fig. 4.

Using the cloud top based parameterisation with the observed cloud top heights (5 and 0.5 degree resolution) and applying a similar rescaling (for the high resolution data figure not shown) the maximum in Central Africa is well reproduced with respect to shape, position and strength for the low resolution data (for the high resolution data, the maximum is located too far northward), whereas in the northern

\footnotetext{
${ }^{6}$ Data from the TRMM 3 A25 data set, derived from the precipitation radar.
} 
part of South America lower values than observed are calculated. Additionally, the highest flash occurrences over South America are shifted southward and to the Andes. In North America the highest flash density is not calculated only in the Southeast, but also more to the West. In Indonesia, flash rates similar to the observed are calculated from the observed cloud top height. The flash densities over the ocean are much smaller than over the continents, in agreement with the observed land-sea contrast. Even though high cloud top heights in the Himalaya region are observed from TRMM, the resulting flash densities are relatively low due to the high surface elevation which leads to a smaller vertical extension of the cloud (maximum vertical extension of the cloud $=$ cloud top height - surface elevation height). The land-sea contrast and the main features of the spatial distribution can be reproduced with these calculations. However, the correlation of the observed flash densities with the calculated flash densities from the observed cloud top heights are similar to those of the model results, with $R=0.74$ for the low resolution and $R=0.69$ for the high resolution TRMM convective cloud top height data. Since the correlation of the calculated flashes from the simulated and observed cloud top heights are similar, this seems to be the maximum accuracy achievable with this parameterisation.

A similar comparison of offline calculated flash frequencies with the A_prec parameterisation is not possible from the 3A25 data since the scheme is designed for strong individual precipitation events with a threshold value of more than $7 \mathrm{~mm} /$ day, which is hardly reached in the monthly averaged TRMM data. Therefore, the 3 hourly precipitation data of the 3B42 TRMM dataset for the year 1999 are applied. From this data set no distinction between stratiform and convective precipitation is available. However, since the parameterisation requires strong precipitation, all rainfall events with values higher than the threshold are selected for the analysis. The resulting annual average flash densities are shown in the lower panel of Fig. 4. It is obvious that the strong land-sea contrast is not represented with this data comparable to the results of the model simulations already analysed in the right column of Fig. 2. In general, the continental lightning activity is underestimated, whereas the oceanic contribution is overestimated compared to the observations. The distribution is comparable to those using the $\mathrm{T} 1, \mathrm{EC}$, and $\mathrm{B} 1$ convection schemes, all producing precipitation distributions which agree relatively well with the observations (Tost et al., 2006). However, the following aspects must be considered when interpreting the results of the flash distribution based on observed precipitation:

- The parameterisation yields only the cloud-to-ground flash frequency whereas the LIS/OTD observations comprise both types of lightning events. For the lower panel of Fig. 4 a globally and temporally constant factor of 0.15 for the ratio between CG to IC flashes has been applied. This is the average value derived from the model results and determines the re-scaling factor without changing the distribution patterns. Although this is a substantial simplification, a spatial and temporal varying ratio cannot be calculated from the observations, preventing the parameterisation from a direct evaluation versus CG flashes.

- The subdivision of precipitation into stratiform and convective rain in the model configurations is quite different from that derived from the monthly mean TRMM data (Tost et al., 2006). Furthermore, not all precipitation must be related to lightning activity. However, a global reduction of the total precipitation by a stratiform fraction would not change the results, and a local distinction within the 3 hourly intervals is not available.

- The time resolution of the satellite is different from that of the model data, since a global coverage cannot be achieved at every $3 \mathrm{~h}$.

The correlation of the derived flash densities from the precipitation approach with the observed ones is $R=0.60$, also comparable to the values obtained with the model.

\subsection{Annual cycle of lightning}

Figure 5 depicts the annual cycle of the spatially averaged (from $60^{\circ} \mathrm{S}$ to $60^{\circ} \mathrm{N}$ ) flash densities in the different simulations. Since the observations are provided as a 110-day running mean, the model output is smoothed in the same way, suppressing the strong day-to-day variations.

As expected from Fig. 3 using the P_cth lightning parameterisation yields a similar annual cycle for all simulations (upper left panel). The black line, depicting the observed annual cycle and the grey shaded area (showing the one $\sigma$ spatial variation), show a strong maximum in boreal summer. This is also captured by the simulations, but the model calculates the highest flash densities about 20 days earlier than observed, independent of the choice of the convection scheme. Furthermore, lower values than observed are simulated (especially with $\mathrm{T} 1$ and $\mathrm{B} 1$, and to a lesser extent with EC). During the boreal winter, in which the lowest lightning occurrence is observed, all simulations substantially overestimate the global average flash frequency by approximately $30 \%$. The overestimation at the beginning of the year occurs mainly in the tropics $\left(10^{\circ} \mathrm{S}\right.$ to $\left.10^{\circ} \mathrm{N}\right)$, since the observations show a substantially smaller maximum during the first crossing of the equator by the ITCZ in boreal spring compared to the second maximum in autumn, whereas in the simulations both crossing events result in similar lightning activity. This results from an overestimation of the lightning activity in the tropical South America with all convection schemes during boreal winter. The lightning activity during summer is captured in better agreement with the observations in each hemisphere $\left(10^{\circ}\right.$ to $\left.30^{\circ}\right)$. However, if the observed TRMM cloud top height is used with the $\mathrm{P}_{\text {_cth }}$ flash parameterisation, the 

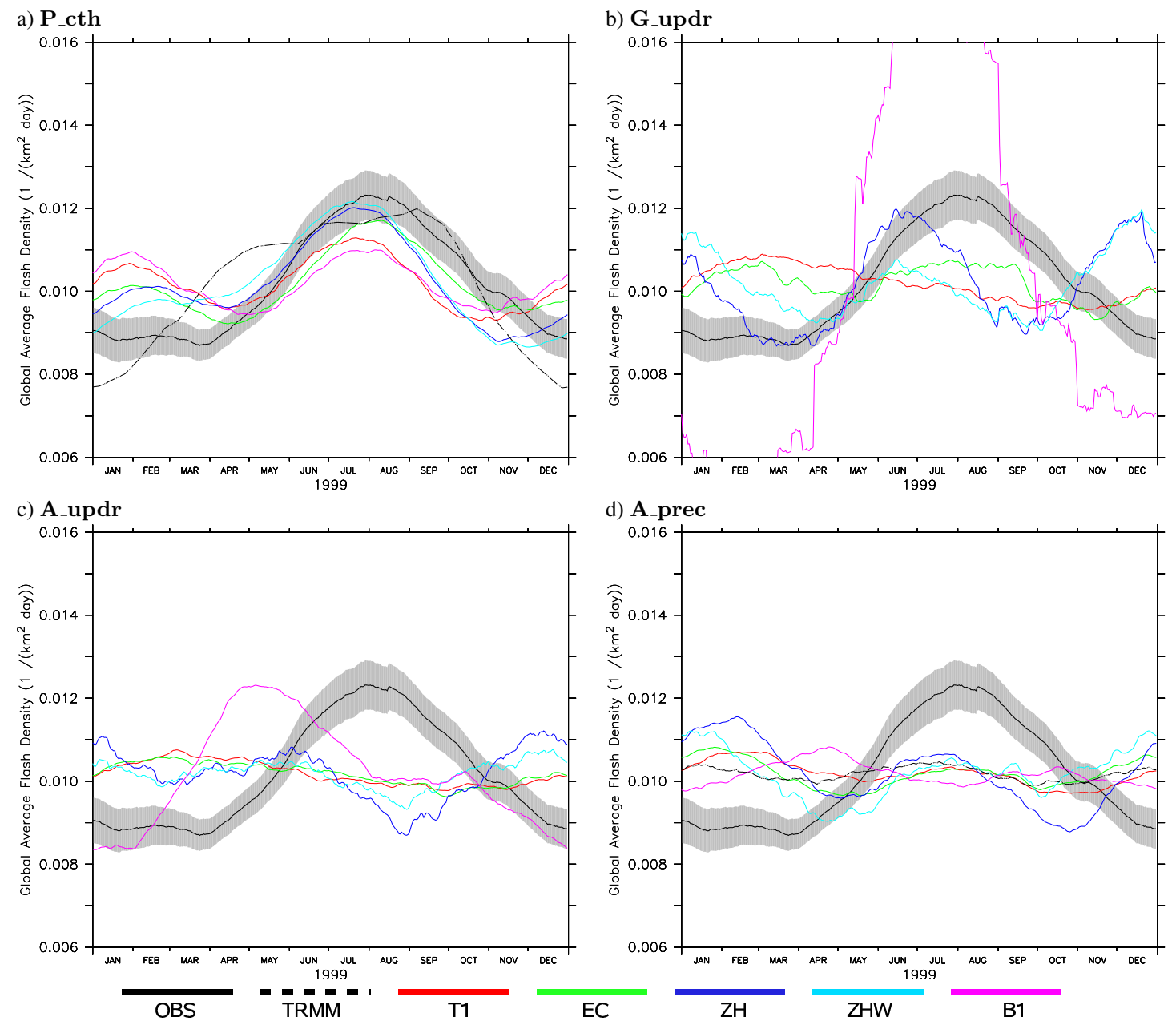

Fig. 5. Average $\left(60^{\circ} \mathrm{S}\right.$ to $60^{\circ} \mathrm{N}$, for the TRMM data only $40^{\circ} \mathrm{S}$ to $\left.40^{\circ} \mathrm{N}\right)$ time series of the flash density for the year 1999 . The four panels show the different lightning schemes. The black line depicts the observations and the grey shaded area the spatial standard deviation. The coloured lines represent the model simulations with the different convection schemes, and the dashed lines the calculated flash densities determined from the TRMM precipitation radar data with the $\mathrm{P}_{-}$cth and the A_prec parameterisations as described in the text.

seasonal cycle of the flash densities does not match the observed one, since double peaked maxima in May and August are calculated with slightly lower values in July (dashed line in the upper left panel of Fig. 5). Nevertheless, the low observed values during boreal winter can be reproduced.

The G_updr (upper right panel of Fig. 5) scheme has much greater difficulty to reproduce the observed annual cycle of lightning activity. In combination with $\mathrm{T} 1$ the temporal variability of the simulated flash densities has no features in common with the observations. Even though the short term variability (not shown) ranges from 0.008 to 0.012 it does not reproduce the seasonal cycle. As for the $\mathrm{P}_{\text {_cth }}$ scheme, the largest differences between the observed and simulated annual cycle occur in the central tropics $\left(10^{\circ} \mathrm{S}\right.$ to $\left.10^{\circ} \mathrm{N}\right)$ showing relatively poor agreement. The changing location of the ITCZ with time cannot be detected in the lightning densities calculated with this parameterisation, largely independent of the convection scheme. This can be explained by the enhanced lightning activity over the oceans, which contributes substantially to the simulated flash densities, but is not observed in such strength. Furthermore, during boreal winter the simulated lightning activity in South America is overestimated leading to the enhanced flash densities in February and March. T1 and EC show a smaller annual variability compared to $\mathrm{ZH}, \mathrm{ZHW}$ and $\mathrm{B} 1$. $\mathrm{ZH}$ and $\mathrm{ZHW}$ also have a substantial contribution of mid-latitude convection with pronounced lightning activity during winter. B1 is characterised by very large temporal extremes (very high day-to-day variations, substantial underestimation in boreal winter, but overestimation during boreal summer). In combination with the poor correlation, indicated by the spatial analysis in Fig. 2, this leads to the conclusion that local extrema govern the flash densities in this simulation setup. 


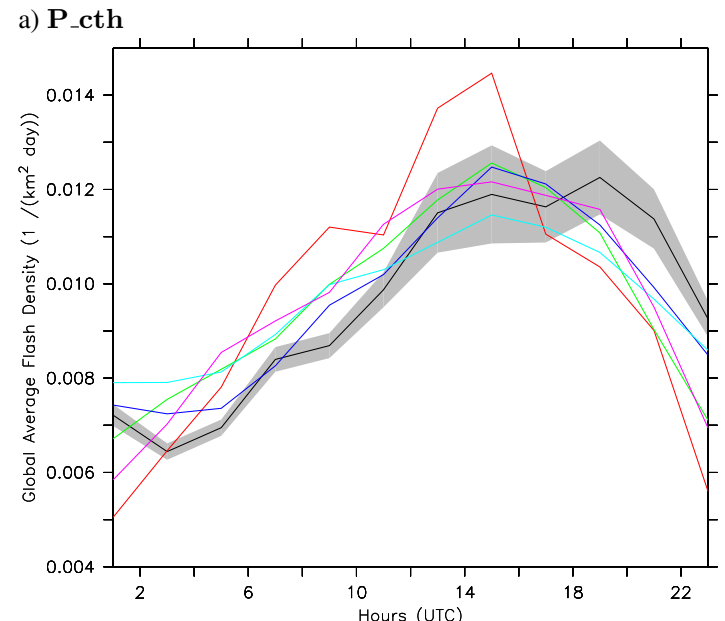

c) A_updr

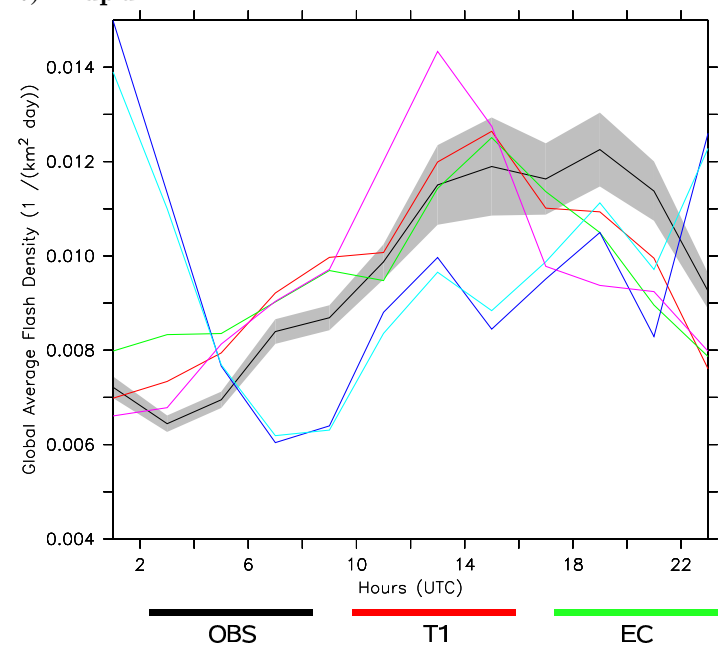

b) G_updr

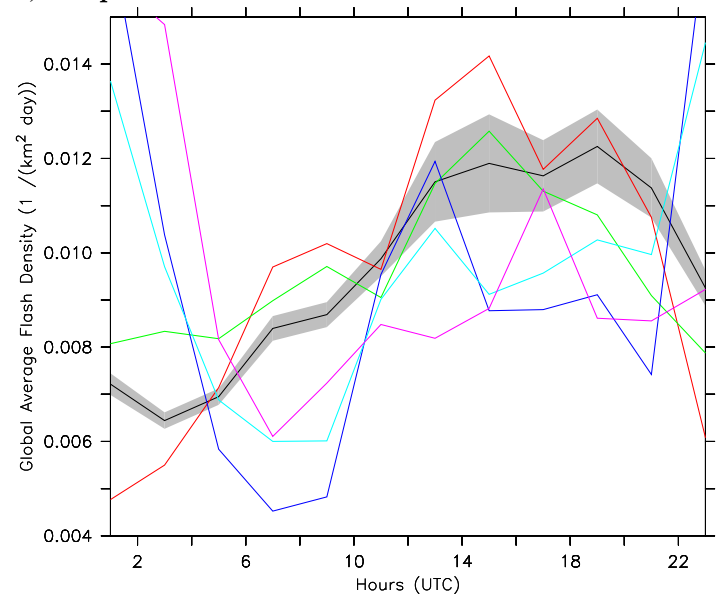

d) A_prec

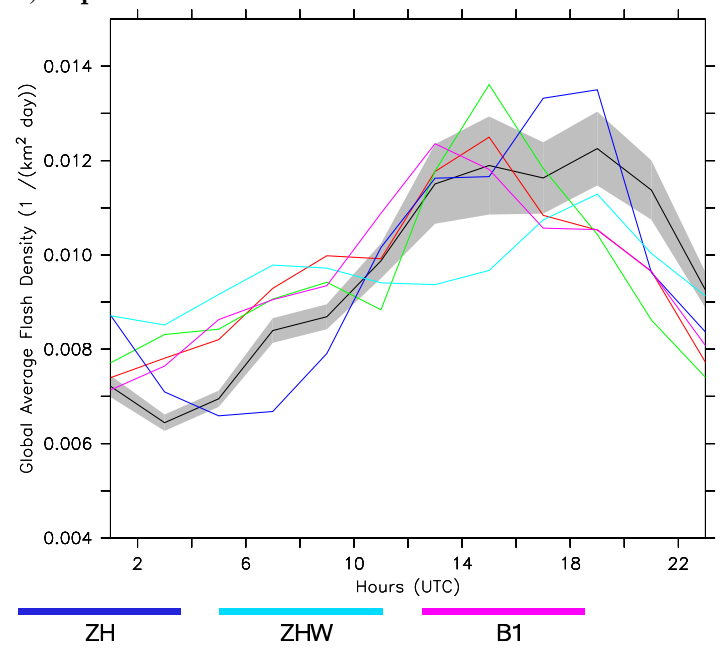

Fig. 6. Global average diurnal time series of the flash density for the year 1999. The four panels show the different lightning schemes. The black line depicts the observations (multi-year climatology) and the grey shaded area the spatial standard deviation (one $\sigma$ ). The coloured lines represent the model simulations with the different convection schemes.

Even though the absolute variability is much lower when the A_updr scheme is used (lower left panel of Fig. 5), the annual cycle can also not be reproduced with this parameterisation. T1 and EC show a very similar behaviour, but have hardly any monthly variation. The other three convection parameterisations are characterised by low values during the maximum of the observations (July, August, September) and higher values than observed during the rest of the year. The reason for this is again found in the central tropics, where the annual cycle is not captured, or is even inverse compared to the observations. Especially B1 shows a boreal spring maximum originating mainly from oceanic convection and lightning activity. This oceanic lighting production with all convection parameterisations also leads to the enhanced flash densities during the boreal winter and contradicts the observed annual cycle.
A similar conclusion is drawn based on the lower right panel of Fig. 5, again showing large discrepancies compared to the observations for all convection schemes when used with the A_prec flash frequency parameterisation. Again, the major differences occur between $10^{\circ} \mathrm{S}$ and $10^{\circ} \mathrm{N}$, the region with the strongest precipitation, and therefore (with this scheme) also lightning activity. Comparing the annual cycle of precipitation of TRMM data in this region with the simulated flash densities from the A_prec parameterisation overall agreement is found, apart from a forward shift of one month in the simulated flashes. However, the derived flash densities from the TRMM data are characterised by a weak seasonal cycle, resulting in overestimated lighting activity during boreal winter and underestimated during the boreal summer.

In conclusion, the lightning schemes which do not use a strict distinction between ocean and land flash parameterisations (G_updr, A_updr and also A_prec in which the 

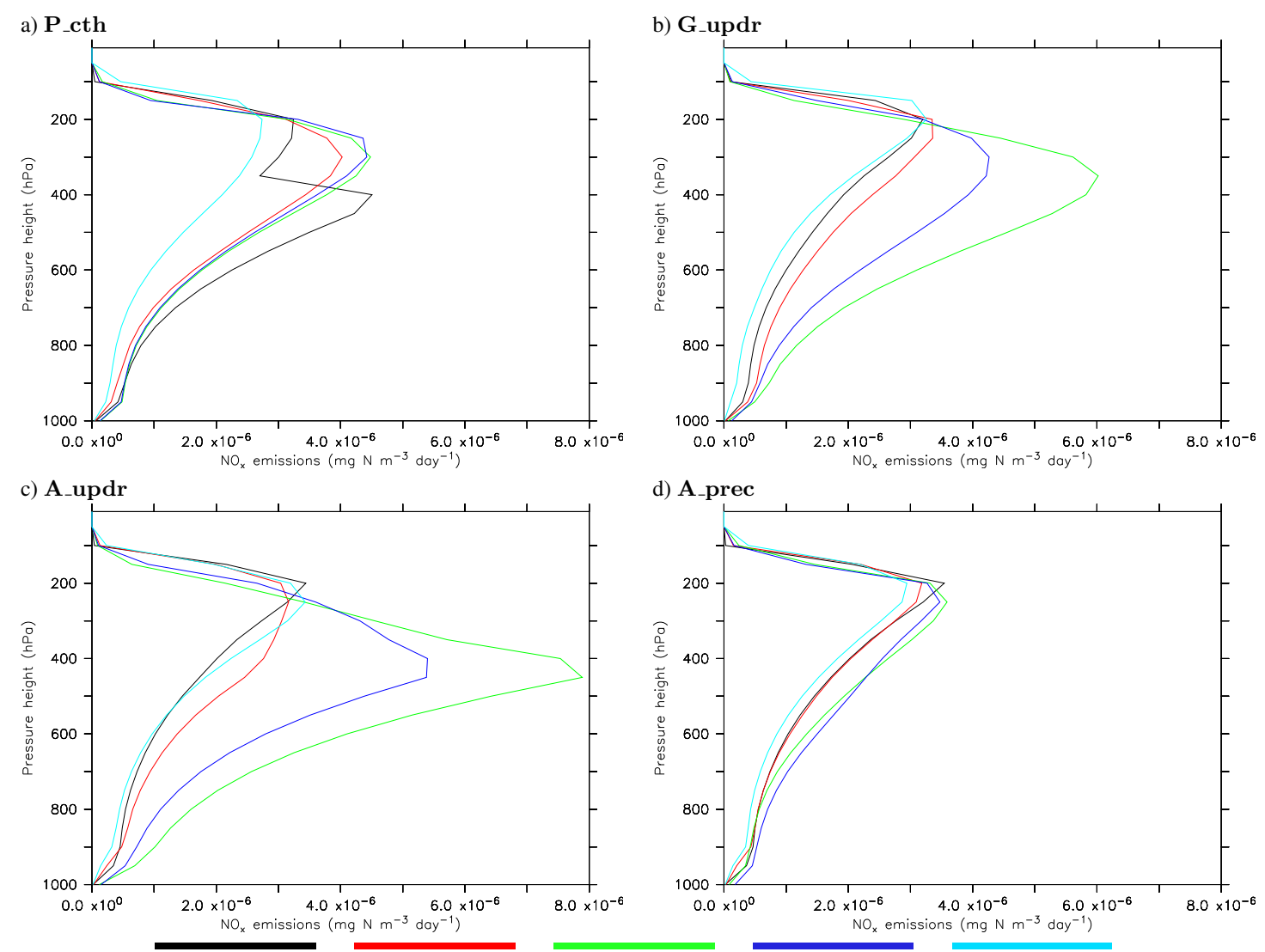

T1

EC

$\mathrm{ZH}$

ZHW

B1

Fig. 7. Vertical profiles of the annual average lightning produced $\mathrm{NO}_{\mathrm{x}}$ emissions, spatially averaged (meridional and zonal, the latter restricted to $60^{\circ} \mathrm{S}-60^{\circ} \mathrm{N}$ ). As in Fig. 5 the panels display the lightning schemes, and the colours the convection parameterisations.

differences in the parameters are not very large) are hardly able to reproduce the seasonal cycle. The reasons are the overestimated oceanic flash occurrences and the incorrectly captured seasonal displacement of regions with intense convection over the oceans.

\subsection{Diurnal cycle of lightning}

In contrast to reproducing the seasonal cycle the diurnal cycle of the flash densities is captured much better by the model simulations, in general for all combinations of convection and lightning parameterisations; only $\mathrm{ZH}$ and $\mathrm{ZHW}$ perform worse in combination with the updraft based lightning parameterisations. Figure 6 depicts the diurnal cycle in UTC. Note that for the observations it is not the daily climatology for 1999, but data from several years, i.e. the "LISOTD_LRADC_V2.2" dataset. The upper left panel, showing the $\mathrm{P}_{-}$cth scheme, is able to reproduce the first flash density maximum at 14:00 UTC (related to the African lightning activity (e.g. Price and Rind, 1994)), but the second maximum which relates to the American early afternoon is generally underestimated. Since the South American flash density is simulated well or even overestimated, this must be related to the underestimation of North American lightning activity. Due to an overestimation of the maximum and the rescaling of the global flash density to the observations, the model mainly underestimates the lightning activity during the rest of the day, especially around midnight. Most of the schemes compute the diurnal cycle almost within one $\sigma$ (spatial variation) of the observations, in agreement with the results of Nickolaenko et al. (2006).

The updraft based approach (G_updr) reproduces the observations well in combination with the T1 convection, especially the double peaked maxima in the afternoon and evening. With the EC convection the diurnal cycle is less pronounced. ZH, ZHW and especially B1, all shown to have problems in our analyses above, also fail with respect to the diurnal cycle, showing maximum values during the night, i.e. highest lightning activity in the western part of South America (late afternoon in the Andes region, compare Fig. 2).

Using the A_updr scheme, the agreement of the T1 and EC simulation with the observations is comparable to the P_cth approach. Again, the North American lightning activity (evening hours in UTC) is underestimated. ZH and ZHW show a similar behaviour as with the G_updr 
parameterisation with highest values around midnight, but with two smaller maxima corresponding to the African and American lightning activity. B1 captures the diurnal cycle comparable to T1, with an overestimation of the first maximum and a phase shift of one hour forward, while the second maximum is not simulated.

The precipitation based flash parameterisation reproduces the major features, but also fails with respect to the second evening maximum. Only with ZHW the amplitude of the diurnal cycle is underestimated. In general, the diurnal cycle represents to some degree also the spatial patterns, since the more intense continental convection usually occurs in the early afternoon. Therefore the diurnal lightning cycle is characterised by a local afternoon maximum.

\section{5 $\quad \mathrm{NO}_{\mathrm{x}}$ emission profiles}

The most important impact of lightning parameterisations in atmospheric chemistry models is on the vertical profiles of the $\mathrm{NO}_{\mathrm{x}}$ emissions. From the calculated flash frequencies using assumptions of total $\mathrm{NO}_{\mathrm{x}}$ emitted per flash, the partitioning of all flashes into CG and IC flashes and the production efficiency of both types (see above in Sect. 2) the total amount of lightning produced $\mathrm{NO}_{\mathrm{x}}$ can be calculated. Using the $\mathrm{C}$-shape profile according to Pickering et al. (1998) a vertical distribution of the emitted $\mathrm{NO}_{\mathrm{x}}$ is determined. Even though the rescaling of the total flash frequency to the LIS/OTD observed frequency is applied, the total amount of emitted $\mathrm{NO}_{\mathrm{x}}$ can differ substantially because of different freezing levels in the convective clouds. This results in different partitioning factors for CG and IC flashes. Since both types are characterised by a different $\mathrm{NO}_{\mathrm{x}}$ production efficiency, different total emissions which are placed between cloud bottom and cloud top level in the C-shape profile (with respect to mixing ratios) (Pickering et al., 1998) are calculated.

Figure 7 depicts average $\mathrm{NO}_{\mathrm{x}}$ emission profiles. The colours denote the convection schemes and the panels the various lightning and subsequent emission parameterisations. The upper left panel (P_cth) exhibits a similar shape for $\mathrm{EC}, \mathrm{ZH}$ and $\mathrm{ZHW}$ after applying the flash frequency rescaling. The double peaked shape of $\mathrm{T} 1$ originates from the differentiation by the convection scheme between deep and midlevel convection (i.e. penetrative convection triggered above the boundary layer). Due to the formulation of the Tiedtke scheme, the second type is artificially restricted to a cloud top of $400 \mathrm{hPa}$, but it globally occurs more often than deep convection. Since the vertical extension of these clouds also extends more than $3 \mathrm{~km}$ they are also considered for possible lightning production and cause the lower peak. Even though the EC convection is also based on the original Tiedtke scheme and distinguishes the same types of convection, the midlevel convection cloud top is not restricted and consequently the second peak is not present. The Bechtold scheme is characterised by the emission maximum at slightly higher altitude (originating from higher cloud top levels), but of smaller magnitude. The latter effect results from the different freezing altitude and consequently the partitioning into cloud-to-ground and intra-cloud flashes.

The application of the G_updr parameterisation leads to a similar shape of the emission profiles for $\mathrm{T} 1, \mathrm{EC}$, and B1. ZHW and even more $\mathrm{ZH}$ show the maximum at lower altitude. The altitude of the maximum emission differs by about $150 \mathrm{hPa}$. Additionally, the overall amounts of emitted $\mathrm{NO}_{\mathrm{x}}$ differ substantially (factor of 2), even though the total number of flashes are rescaled to the observations. Additionally, the emissions in the mid-troposphere are substantially enhanced with $\mathrm{ZH}$ and ZHW.

A similar result is obtained when using A_updr with the different convection schemes: T1, EC, and B1 are similar in emission strength and the altitude of the maximum emission level, whereas for $\mathrm{ZH}$ and $\mathrm{ZHW}$ the maximum is located substantially lower, while the total amount of emitted $\mathrm{NO}_{\mathrm{x}}$ is much larger. As with $\mathrm{G}_{-}$updr the emissions are much stronger between 400 and $700 \mathrm{hPa}$ using $\mathrm{ZH}$ or ZHW.

The precipitation based lightning scheme (A_prec, lower right panel of Fig. 7), shows approximately the same maximum emission altitude for all convection parameterisations. The total amount of emitted $\mathrm{NO}_{\mathrm{x}}$ varies by $20 \%$, being highest for $\mathrm{T} 1$ and $\mathrm{ZH}$, and lowest for $\mathrm{B} 1$, while the overall shape of the emission profiles is similar.

In summary, using the different combinations of schemes results in very different distributions of $\mathrm{NO}_{\mathrm{x}}$ from lightning, even in the averaged profiles. In combination with the large temporal and spatial differences in the flash densities it is obvious that the effective emissions of $\mathrm{NO}_{\mathrm{x}}$ produced by lightning shows a wide range. The most realistic emission profiles cannot be determined from this study, but the evaluation of the impacts of these emissions on atmospheric chemistry is beyond the scope of this work and will be analysed separately.

\subsection{Dependencies on the model resolution and setup}

Most of the lightning parameterisations take the dependence on the horizontal resolution into account, mainly by a rescaling factor (determined from the ratio of the model grid size to a reference area) that is multiplied with the flash rate. However, for some model configurations this is not sufficient. Instead, a new set of parameters is required to give a better representation of the different convective conditions caused by the change in resolution. A sensitivity simulation using the $\mathrm{T} 1$ convection scheme, but a lower vertical resolution (19 levels, but the midpoint of the uppermost layer also at $10 \mathrm{hPa}$ ) results in strong differences in combination with the G_updr scheme, due to differences in the convective updraft mass fluxes. For instance, the spatial distribution is captured similarly, the required rescaling factor is lower and the seasonal cycle of the lightning activity is represented much better in this model configuration compared to the 31 layer version 
discussed above. The results are comparable to those obtained with the P_cth scheme. This leads to the conclusion that the vertical resolution is quite relevant for the parameterised convective dynamics. Consequently the parameters of the lightning scheme must be adjusted with respect to the vertical resolution of the model.

Even though the application of the nudging technique in the simulation setup has the advantage of reproducing the large-scale circulation close to reality (and therefore enables direct comparison with observations), it also has some drawbacks: The simulated meteorology is continuously perturbed by the nudging tendency. In combinations with some convection schemes this causes a lower frequency of deep convective activity, since the boundary layer stability directly or indirectly determines the triggering of the convection algorithm. The nudging causes slightly enhanced atmospheric stability throughout the troposphere, since for the nudged temperature profiles, convection and boundary layer parameterisations have been applied within the data assimilating model (ECMWF forecast model). Consequently, a simulation without nudging shows substantially stronger average updraft mass fluxes in the middle and upper troposphere (Tost, 2006).

\subsection{Potential weaknesses of the convection schemes}

The analysis of the simulated lightning data in combination with the observations also indicates some weaknesses in the convection schemes:

- The convective cloud top heights differ substantially, as can be seen from the range of the rescaling factors for the P_cth lightning parameterisation and also from the direct comparison of the cloud top heights. Furthermore, observed and simulated cloud top heights show significant differences, comparable to the study of Kurz and Grewe (2002).

This becomes most pronounced in South America, where in contrast to the observations, the convection reaches deeper with most convection parameterisations than in Central Africa. The agreement of simulated and observed cloud top heights from TRMM is better with T1, EC and B1 (overestimated over the tropical oceans), whereas ZH and ZHW show substantially higher cloud tops over both the continents and the oceans.

- The convection schemes of ZH and ZHW simulate a too high frequency of convective lightning events if the P_cth lightning scheme is used.

- The restriction of midlevel convection below $400 \mathrm{hPa}$ in the $\mathrm{T} 1$ convection parameterisation appears to be artificial. The explicit distinction between deep convection originating close to the surface and penetrative convection starting at higher altitude is rather arbitrary, and only applied in the T1 scheme. The EC scheme, also being developed from the original Tiedtke (1989) scheme, but treating midlevel convection similar to deep convection, does not contain such a clear distinction.

- Even though the convective mass fluxes agree relatively well with respect to the zonal averages (Tost, 2006), the updraft strength of individual convective events can be too strong and/or too localised (especially with B1). On the other hand, the average vertical velocities in $\mathrm{ZH}$ and ZHW appear to be much lower (very high rescaling factors are required in the updraft based lightning schemes), and the convective mass fluxes in the middle and upper troposphere are lower compared to the other schemes. However, this is partly caused by the applied nudging technique as explained above.

- Oceanic convection is almost as intense as continental convection with respect to the updraft strength (contradicting the assumption of the updraft based lightning parameterisation), since the parameterisations provide only grid box mean updraft mass fluxes. The convective precipitation over the tropical oceans is too high (see Tost et al., 2006), leading to an overestimation of the flash frequencies from the A_prec parameterisation over the ocean.

- Even though the influence of subgrid-scale convection on the humidity and moist static energy is captured accurately by the parameterisations independent of the model resolution, the convective dynamics can be substantially influenced by the selected model resolution (both horizontal and vertical), affecting both lightning schemes and convective tracer transport.

\section{Conclusions}

Using parameterised model results (convection) as input data for another parameterisation (lightning) leads to large uncertainties in the prediction of flashes and additionally parameterised lightning $\mathrm{NO}_{\mathrm{x}}$ emissions. For all combinations of lightning and convection schemes a scaling factor (in addition to the a priori performed resolution dependent rescaling) must be applied to reproduce the observed global flash frequency, and these factors can differ by orders of magnitude. With none of the combinations is it possible to accurately reproduce the observed lightning distributions, although some combinations produce more realistic results than others.

The P_cth approach offers robustness with respect to both spatial and temporal variations of the convective events, but cloud top height is only indirectly (less physically) linked with cloud electrification via the vertical extension of the clouds which is affected by the strength of the updraft. The updraft approaches must be used with caution, especially the G_updr scheme, since the exponential formulation tends to create unrealistically high values for strong updrafts. However, in combination with $\mathrm{T} 1$ this approach is among the best 
in reproducing the observed lightning densities. This results mainly from the development of the G_updr scheme in combination with this specific convection scheme in a previous model version (ECHAM4, Grewe et al. (2001); Kurz and Grewe (2002)). The precipitation approach has shown to perform reasonably well for the long-term average, if the observed precipitation distribution is reproduced (e.g. by B1), whereas the temporal variability is poorly captured.

We conclude that the rescaling to the globally observed flash frequency is not sufficient, and additional tuning of the parameters is required. This procedure, however, is beyond the scope of this study. A re-determination of the coefficients is also desirable for the two approaches by Allen and Pickering (2002), but this is also not straight-forward, since either global information about the CG fraction of the lightning events (which cannot be easily determined from LIS/OTD data), or a completely new set of parameters for the total flash frequency for each model configuration are required. The resulting parameters would have comparable uncertainties (=variations) as the existing parameterisation approaches. Furthermore, it appears that except for the P_cth approach the lightning parameterisations are hardly robust against changes in the convective dynamics. The drawback is the requirement of a continously re-tuning of the parameters. Under the perturbed conditions of future scenarios such a re-tuning is almost impossible.

The seasonal cycle is difficult to reproduce with all combinations, indicating general problems with the model configurations, resolutions or the parameterisation concepts.

Even if the lightning events agree with the observations, the resulting $\mathrm{NO}_{\mathrm{x}}$ emissions deviate due to the different convective cloud properties (freezing level, distinction between cloud-to-ground and intra-cloud flashes, etc.). From the results it is not possible to decide which emission profiles are most realistic, since direct emissions are not observed. Only the combination of lightning emissions with a chemistry model can be evaluated e.g. using aircraft observations in the anvil regions of convective clouds. This will be the focus of an upcoming study. The large variability associated with the tested combinations points to many unresolved problems in simulating lightning and lightning produced $\mathrm{NO}_{\mathrm{x}}$ emissions in atmospheric general circulation models.

For future model simulations some approaches, e.g. the high correlation between precipitation ice and flash frequencies (Petersen et al., 2005) are promising, though they require improvements of both, the convection parameterisations with respect to ice microphysics and the development of a scheme that makes use of this relationship.

\section{Appendix A}

\section{Abbreviations}

\begin{tabular}{|c|c|}
\hline$\sigma$ & 1) standard deviation \\
\hline & 2) ratio of pressure to surface pressure $\left(p / p_{s}\right)$ \\
\hline$\sigma_{\text {sim }}$ & standard deviation of the simulation results \\
\hline$\sigma_{\text {obs }}$ & standard deviation of the observations \\
\hline$\sigma^{\star}$ & $\sigma_{\mathrm{sim}} / \sigma_{\mathrm{obs}}$ \\
\hline$R$ & correlation \\
\hline RMSE & root mean square error \\
\hline CG flashes & cloud-to-ground flashes \\
\hline IC flashes & inter- and intra-cloud flashes \\
\hline GCM & General Circulation Model \\
\hline AC-GCM & Atmospheric Chemistry General Circulation Model \\
\hline ECMWF & European Centre for Medium Range Weather Forecast \\
\hline E5/M1 & ECHAM5/MESSy1 \\
\hline MATCH & Model of Atmospheric Transport and Chemistry \\
\hline LNOX & $\mathrm{NO}_{\mathrm{x}}$ emissions from lightning (submodel) \\
\hline TRMM & Tropical Rainfall Measuring Mission \\
\hline ITCZ & Inner Tropical Convergence Zone \\
\hline SPCZ & Southern Pacific Convergence Zone \\
\hline LIS & Lightning Imaging Sensor \\
\hline OTD & Optical Transient Detector \\
\hline $\begin{array}{l}\text { LISOTD_ } \\
\text { LRTS_V2.2 }\end{array}$ & $\begin{array}{l}\text { Low resolution time series dataset of combined flash rates } \\
\text { from LIS and OTD }\end{array}$ \\
\hline $\begin{array}{l}\text { LISOTD_ } \\
\text { LRADC_V2.2 }\end{array}$ & $\begin{array}{l}\text { Low resolution annual diurnal climatology dataset of } \\
\text { combined flash rates from LIS and OTD }\end{array}$ \\
\hline T1 & Tiedtke-Nordeng convection scheme \\
\hline EC & convection scheme from ECMWF \\
\hline $\mathrm{ZH}$ & convection scheme of Zhang-McFarlane-Hack \\
\hline ZHW & $\begin{array}{l}\text { convection scheme of Zhang-McFarlane-Hack with addi- } \\
\text { tional evaporation following Wilcox }\end{array}$ \\
\hline B1 & convection scheme of Bechtold \\
\hline P_cth & $\begin{array}{l}\text { lightning parameterisation based on cloud top height } \\
\text { (Price and Rind) }\end{array}$ \\
\hline G_updr & $\begin{array}{l}\text { lightning parameterisation based on vertical velocity } \\
\text { (Grewe) }\end{array}$ \\
\hline A_updr & $\begin{array}{l}\text { lightning parameterisation based on vertical velocity } \\
\text { (Allen and Pickering) }\end{array}$ \\
\hline A_prec & $\begin{array}{l}\text { lightning parameterisation based on convective surface } \\
\text { precipitation (Allen and Pickering) }\end{array}$ \\
\hline
\end{tabular}

Acknowledgements. We thank $\mathrm{H}$. Christian and co-workers, providing the detailed lightning satellite observation data. We are grateful to the TRMM satellite team for providing the datasets. We thank V. Grewe and C. Kurz for helpful comments to this manuscript and contributions to the LNOX submodel development, and all the other MESSy developers for their support. Additionally, we thank the three referees for the helpful comments. Furthermore, we wish to acknowledge the use of the Ferret program for analysis and graphics in this paper. Ferret is a product of NOAA's Pacific Marine Environmental Laboratory. (Information is available at http://ferret.pmel.noaa.gov/Ferret/). This study is part of the ENIGMA project; we thank the Max-Planck Society for support.

Edited by: M. Dameris 


\section{References}

Allen, D. J. and Pickering, K. E.: Evaluation of lightning flash rate parameterizations for use in a global chemical transport model, J. Geophys. Res., 107, 4711, doi:10.1029/2002JD002066, 2002.

Barthe, C., Molinié, G., and Pinty, J.-P.: Description and first results of an explicit electrical scheme in a 3D cloud resolving model, Atmos. Res., 76, 95-113, 2005.

Bechtold, P., Bazile, E., Guichard, F., Mascart, P., and Richard, E.: A mass-flux convection scheme for regional and global models, Q. J. Roy. Meteor. Soc., 127, 869-886, 2001.

Bechtold, P., Chaboureau, J.-P., Beljaars, A., Betts, A. K., Köhler, M., Miller, M., and Redelsperger, J.-L.: The simulation of the diurnal cycle of convective precipitation over land in a global model, Q. J. Roy. Meteor. Soc., 130, 3119-3137, 2004.

Christian, H. J., Blakeslee, R. J., Goodman, S. J., Mach, D. A., Stewart, M. F., Buechler, D. E., Koshak, W. J., Hall, J. M., Boek, W. L., Driscoll, K. T., and Boccippio, D. J.: The Lightning Imaging Sensor, in: Proceedings of the 11th International Conference on Atmospheric Electricity, Guntersville, Alabama, 7-11 June , 746-749, 1999.

Christian, H. J., Blakeslee, R. J., Boccippio, D. J., Boeck, W. L., Buechler, D. E., Driscoll, K. T., Goodman, S. J., Hall, J. M., Koshak, W. J., Mach, D. M., and Stewart, M. F.: Global frequency and distribution of lightning as observed from space by the Optical Transient Detector, J. Geophys. Res., 108, 4005, doi: 10.1029/2002JD002347, 2003.

Grewe, V., Brunner, D., Dameris, M., Grenfell, J. L., Hein, R., Shindell, D., and Staehelin, J.: Origin and variability of upper tropospheric nitrogen oxides and ozone at northern mid-latitudes, Atmos. Environ., 35, 3421-3433, 2001.

Hack, J. J.: Parameterization of moist convection in the National Center for Atmospheric Research community climate model (CCM2), J. Geophys. Res., 99, 5551-5568, 1994.

Jacobson, M. Z.: Atmopsheric Pollution, Cambridge University Press, 2002.

Jeuken, A. B. M., Siegmund, P. C., Heijboer, L. C., Feichter, J., and Bengtsson, L.: On the potential of assimilating meteorological analyses in a global climate model for the purpose of model validation, J. Geophys. Res., 101, 16939-16950, 1996.

Jöckel, P., Sander, R., Kerkweg, A., Tost, H., and Lelieveld, J.: Technical Note: The Modular Earth Submodel System (MESSy) - a new approach towards Earth System Modeling, Atmos. Chem. Phys., 5, 433-444, 2005,

http://www.atmos-chem-phys.net/5/433/2005/.

Jöckel, P., Tost, H., Pozzer, A., Brühl, C., Buchholz, J., Ganzeveld, L., Hoor, P., Kerkweg, A., Lawrence, M. G., Sander, R., Steil, B., Stiller, G., Tanarhte, M., Taraborrelli, D., van Aardenne, J., and Lelieveld, J.: The atmospheric chemistry general circulation model ECHAM5/MESSy1: consistent simulation of ozone from the surface to the mesosphere, Atmos. Chem. Phys., 6, 50675104, 2006,

http://www.atmos-chem-phys.net/6/5067/2006/.

Kummerow, C., Simpson, J., Thiele, O., Barnes, W., Chang, A. T. C., Stocker, E., Adler, R. F., Hou, A., Kakar, R., Wentz, F., Ashcroft, P., Kozu, T., Hong, Y., Okamoto, K., Iguchi, T., Kuroiwa, H., Im, E., Haddad, Z., Huffman, G., Ferrier, B., Olson, W. S., Zipser, E., Smith, E. A., Wilheit, T. T., North, G., Krishnamurti, T., and Nakamura, K.: The Status of the Tropical Rainfall Measuring Mission (TRMM) after two years in orbit, J.
Appl. Meteorol., 39, 1965-1982, 2000.

Kurz, C. and Grewe, V.: Lightning and thunderstorms, Part I: Observational data and model results, Met. Zeitschr., 11, 379-393, doi:10.1127/0941-2498/2002/0011-0379, 2002.

Labrador, L. J., v. Kuhlmann, R., and Lawrence, M. G.: The effects of lightning-produced $\mathrm{NO}_{\mathrm{x}}$ and its vertical distribution on atmospheric chemistry: sensitivity simulations with MATCH-MPIC, Atmos. Chem. Phys., 5, 1815-1834, 2005, http://www.atmos-chem-phys.net/5/1815/2005/.

Lawrence, M. G., Crutzen, P. J., Rasch, P. J., Eaton, B. E., and Mahowald, N. M.: A model for studies of tropospheric chemistry: Description, global distributions and evaluation, J. Geophys. Res., 104, 26 245-26 277, 1999.

Nickolaenko, A. P., Hayakawa, M., and Sekiguchi, M.: Variations in global thunderstorm activity inferred from the OTD records, Geophys. Res. Lett., 33, L06823, doi:10.1029/2005GL024884, 2006.

Nordeng, T. E.: Extended versions of the convective parametrization scheme at ECMWF and their impact on the mean and transient activity of the model in the tropics, Tech. Rep. 206, ECWMF, 1994.

Petersen, W. A. and Rutledge, S. A.: On the relationship between cloud-to-ground lightning and convective rainfall, J. Geophys. Res., 103, 14 025-14 040, 1998.

Petersen, W. A., Christian, H. J., and Rutledge, S. A.: TRMM observations of the global relationship between ice water content and lightning, Geophys. Res. Lett., 32, L14819, doi:10.1029/ 2005GL023236, 2005.

Pickering, K. E., Wang, Y., Tao, W.-K., Price, C., and Müller, J.F.: Vertical distribution of lightning $\mathrm{NO}_{\mathrm{x}}$ for use in regional and chemical transport models, J. Geophys. Res., 103, 31203 $31216,1998$.

Price, C. and Rind, D.: A simple Lightning Parametrization for Calculating Global Lightning Distributions, J. Geophys. Res., 97, 9919-9933, 1992.

Price, C. and Rind, D.: What determines the Cloud-to-Ground Lightning fraction in Thunderstorms, Geophys. Res. Lett., 20, 463-466, 1993.

Price, C. and Rind, D.: Modeling Global Lightning Distributions in a General Circulation Model, Mon. Weather Rev., 122, 1930 1939, 1994.

Price, C., Penner, J., and Prather, M.: $\mathrm{NO}_{\mathrm{x}}$ from lightning, 1. Global distribution based on lightning physics, J. Geophys. Res., 102, 5929-5941, 1997a.

Price, C., Penner, J., and Prather, M.: $\mathrm{NO}_{\mathrm{x}}$ from lightning, 2. Constraints from the global atmospheric electric circuit, J. Geophys. Res., 102, 5943-5951, 1997b.

Rasch, P. J., Mahowald, N. M., and Eaton, B. E.: Representations of transport, convection and the hydrologic cycle in chemical transport models: Implications for the modeling of short-lived and soluble species, J. Geophys. Res., 102, 28 127-28 138, 1997.

Roeckner, E., Bäuml, G., Bonaventura, L., Brokopf, R., Esch, M., Giorgetta, M., Hagemann, S., Kirchner, I., Kornblue, L., Manzini, E., Rhodin, A., Schleese, U., Schulzweida, U., and Tompkins, A.: The atmospheric general circulation model ECHAM5: Part 1, Tech. Rep. 349, Max-Planck-Institut für Meteorologie, 2003.

Roeckner, E., Brokopf, R., Esch, M., Giorgetta, M., Hagemann, S., Kornblue, L., Manzini, E., Schleese, U., and Schulzweida, U.: 
The atmospheric general circulation model ECHAM5: Part 2, Tech. Rep. 354, Max-Planck-Institut für Meteorologie, 2004.

Roeckner, E., Brokopf, R., Esch, M., Giogetta, M., Hagemann, S., Kornblueh, L., Manzini, E., Schleese, U., and Schulzweida, U.: Sensitivity of simulated climate to horizontal and vertical resolution in the ECHAM5 atmosphere model, J. Climate, 19, 37713791, 2006.

Schumann, U. and Huntrieser, H.: The global lightning-induced nitrogen oxides source, Atmos. Chem. Phys., 7, 3823-3907, 2007, http://www.atmos-chem-phys.net/7/3823/2007/.

Taylor, K. E.: Summarizing multiple aspects of model preformance in a single diagram, J. Geophys. Res., 106, 7183-7192, 2001.

Thomas, R. J., Krehbiel, P. R., Rison, W., Hamlin, T., Boccippio, D. J., Goodman, S. J., and Christian, H. J.: Comparison of ground-based 3-dimensional lightning mapping observations with satellite-based LIS observations in Oklahoma, Geophys. Res. Lett., 27, 1703-1706, 2000.

Tiedtke, M.: A Comprehensive Mass Flux Scheme for Cumulus Parametrization in Large-Scale Models, Mon. Weather Rev., 117, 1779-1800, 1989.

Tost, H.: Global Modelling of Cloud, Convection and Precipitation Influences on Trace Gases and Aerosols, Ph.D. thesis, Rheinische Friedrich-Wilhelms-Universität Bonn, Germany, available at: http://hss.ulb.uni-bonn.de/diss_online/math_nat_fak/ 2006/tost_holger, 2006.
Tost, H., Jöckel, P., and Lelieveld, J.: Influence of different convection parameterisations in a GCM, Atmos. Chem. Phys., 6, 54755493, 2006, http://www.atmos-chem-phys.net/6/5475/2006/.

van Aalst, M. K., van den Broek, M. M. P., Bregman, A., Brühl, C., Steil, B., Toon, G. C., Garcelon, S., Hansford, G. M., Jones, R. L., Gardiner, T. D., Roelofs, G.-J., Lelieveld, J., and Crutzen, P.: Trace gas transport in the 1999/2000 Arctic winter: comparison of nudged GCM runs with observations, Atmos. Chem. Phys., 4, 81-93, 2004,

http://www.atmos-chem-phys.net/4/81/2004/.

Wilcox, E. M.: Spatial and Temporal Scales of Precipitation Tropical Cloud Systems in Satellite Imagery and the NCAR CCM3, J. Climate, 16, 3545-3559, 2003.

Zhang, G. J. and McFarlane, N. A.: Sensitivity of Climate Simulations to the Parameterization of Cumulus Convection in the Canadian Climate Centre General Circulation Model, Atmosphere-Ocean, 33, 407-446, 1995. 